\title{
PREPARATION OF BORIC ACID MODIFIED EXPANDABLE GRAPHITE AND ITS INFLUENCE ON POLYETHYLENE COMBUSTION CHARACTERISTICS
}

\author{
HONGMEI ZHAO ${ }^{a, b}$, XIUYAN PANG ${ }^{a *}$, RUINIAN LIN ${ }^{a}$ \\ allege of Chemistry and Environmental Science, Key Laboratory of Analytical Science and Technology of Hebei Province, \\ Hebei University, Baoding 071002, PR China \\ ${ }^{b}$ Department of VIP, Affiliated Hospital of Hebei University, Baoding, Hebei 071000, PR China
}

\begin{abstract}
A boric acid modified expandable graphite $\left(\mathrm{EG}_{\mathrm{B}}\right)$ was prepared through oxidizing-intercalating reaction of natural graphite, using $\mathrm{H}_{2} \mathrm{SO}_{4}$ and boric acid $\left(\mathrm{H}_{3} \mathrm{BO}_{3}\right)$ as intercalators simultaneously. The dilatability of the intercalated products were characterized with expansion volume and initial expansion temperature. Scanning electron microscope, X-ray diffraction spectroscopy, energy dispersive spectroscopy and Fourier transform infrared spectroscopy were employed to detect its layer structure, main element relative contents and function group. At the same time, its influence on combustion characteristics and thermal stability for linear low density polyethylene (LLDPE) were investigated in limiting oxygen index (LOI) tests, vertical burning tests and thermal gravimetric/differential thermal gravimetric analyses. Comparing with the normal expandable graphite (EG, intercalated by single $\left.\mathrm{H}_{2} \mathrm{SO}_{4}\right), \mathrm{EG}_{\mathrm{B}}$ exhibited high dilatability, thermal stability and flame retardancy for LLDPE. It had been testified by combustion tests that the addition of $30 \mathrm{wt} \% \mathrm{EG}_{\mathrm{B}}$ to LLDPE improved the limiting oxygen index (LOI) from $17.6 \%$ to $30.2 \%$, and the vertical burning level of UL-94 standard reached V-0 level. Whereas, the LOI of the same amount referenced EG was only $25.1 \%$, the UL94 level only reached V-1. Moreover, the synergistic effect between $\mathrm{EG}_{\mathrm{B}}$ and ammonium polyphosphate (II) (APP) improved the LOI of 70LLDPE/10APP/20EG composite to $33.0 \%$, and the UL-94 level to V-0. The synergistic efficiency was attributed to the formation of continuous and compact residual char.
\end{abstract}

Keywords: Modified expandable graphite; boric acid; characteristics; dilatability; flame retardancy; synergistic efficiency.

\section{INTRODUCTION}

Natural graphite is a kind of carbon material with layer structure, intercalator such as sulfuric acid can be included between the carbon layers in chemical or electronic chemical oxidation reaction, ${ }^{1,2}$ and then graphite intercalating compound (GIC) named expandable graphite (EG) is obtained. EG is known as a new generation of intumescent flame retardant (IFR) for its good capability of halogen-free, non-dropping and low-smoke. ${ }^{3,4}$ This retardant acts in both the condensed and gas phase through an endothermic reaction: 5,6 (1) when contacting with flame source, EG will instantly expand and turn into swollen multicellular "graphite worms" covering on the retarded polymer surface, which is in favor of slowing down the heat and mass transfer and interrupting the degradation of polymer matrix. (2) In oxidation reaction with $\mathrm{H}_{2} \mathrm{SO}_{4}$ at high temperature, it releases gases such as $\mathrm{CO}_{2}, \mathrm{H}_{2} \mathrm{O}$ and $\mathrm{SO}_{2}, 3$, ${ }^{7-9}$ which can reduce concentration of combustible gas; thereby char formation has been enhanced. (3) Expansion of EG will consume an enormous amount of heat, which is helpful to decrease the combustion temperature and rate.

Due to its outstanding anti-flame capability, EG has been used in the flame retardance of polymer materials such as polyurethane (PU) or polyurethane coatings, ${ }^{10,11}$ polyolefin blends, ${ }^{12,13}$ acrylonitrile-butadiene-styrene (ABS), ${ }^{14,15}$ ethylene vinyl acetate (EVA). ${ }^{16,17}$ However, there are still some shortcomings when EG is used as a FR. Firstly, due to its limited efficiency, a normal 30 $\mathrm{wt} \%$ dose is needed to achieve satisfying effect, ${ }^{18}$ which often leads to obvious deterioration of the mechanical properties. Moreover, more $\mathrm{SO}_{2}$ will emit when EG is prepared with only $\mathrm{H}_{2} \mathrm{SO}_{4}$ as intercalator. ${ }^{19}, 20$ So it is very important to enhance efficiency in order to meet environmental protection standard.

Measures have been attempted to improve EG flame retardancy and reduce its dose. Addition of EG together with other synergistic FRs such as phosphonate, ${ }^{21}$ polyphosphate, ${ }^{22}$ phosphorus, ${ }^{23}$ metal hydroxide, ${ }^{12}$ layered double hydroxide, ${ }^{24}$ silica, ${ }^{25}$ had been tested, and results indicated the addition of other synergistic FRs can normally improve flame retardancy and reduce EG dose. Surface treatments had been also reported to improve EG miscibility with polymer matrices. Hao et al prepared an EG modified with silane coupling agent and boric acid, ${ }^{26}$ and its application for PU indicated that thermal stability of the modified EG and its flame retardancy for PU composites were all higher than that of normal EG. While, the ground EG treated with phosphoric acid and silane presented an obvious increase of volume expansion ratio, ${ }^{15}$ and addition of the treated EG in ABS significantly enhanced the fire performance but decreased the impact strength of ABS. Whereas, the improvement by combined addition or EG modification is usually very limited, especially the simple mix of EG with other retardants. ${ }^{17}$ The main reason should be the insufficient mix caused by the inconsistence of particle size, density, polarity and addition dosage between these FRs and matrix.

It is worthy to note that non-carbon substance can easily move into the graphite layers and form GIC with accordant components. ${ }^{27}$ Therefore, if a FR is used as assistant intercalator, the combined retardant can be prepared through graphite intercalating reaction, which can not only reduce sulfur content in GIC, but also improve the mix uniformity and then improve EG dilatability and flame retardancy. It was reported the $\mathrm{H}_{2} \mathrm{SO}_{4}$ /APP (APP, ammonium polyphosphate, a assistant intercalating agent) GIC, prepared through two-step method, exhibited a higher expansion volume (EV, $\left.240 \mathrm{~mL} \mathrm{~g}^{-1}\right)$ than that of the $\mathrm{H}_{2} \mathrm{SO}_{4}$ intercalated $\mathrm{EG}\left(210 \mathrm{~mL} \mathrm{~g}^{-1}\right) .{ }^{19} \mathrm{An} \mathrm{EG}$, intercalated by $\mathrm{H}_{2} \mathrm{SO}_{4}$ and $\mathrm{Na}_{2} \mathrm{SiO}_{3}$ through two-step intercalation reaction, ${ }^{17}$ presented an EV of $517 \mathrm{~mL}$ $\mathrm{g}^{-1}$ and combustion limiting oxygen index (LOI) of $28.7 \%$ for EVA. However, the EV of referenced EG, which is intercalated by only $\mathrm{H}_{2} \mathrm{SO}_{4}$ was merely 433 $\mathrm{mL} \mathrm{g}^{-1}$, and the LOI was just $24.4 \%$. At the same time, its relative sulfur content decreased from $1.79 \%$ to $1.23 \%$. Especially, the intercalated $\mathrm{Na}_{2} \mathrm{SiO}_{3}$ in $\mathrm{EG}$ is more effectual in improving the flame retardancy than the direct addition of $\mathrm{Na}_{2} \mathrm{SiO}_{3} \cdot 9 \mathrm{H}_{2} \mathrm{O}$ with EG.

According to the former researches, $\mathrm{B}$ and boric acid $\left(\mathrm{H}_{3} \mathrm{BO}_{3}\right)$ have been widely used as oxidation inhibitors to improve the thermal stability of carbon materials. With boron oxide as precursor, ${ }^{28}$ the $\mathrm{B}$ modified carbon fiber reinforce carbon (CFRC) composite could be prepared with soaking or direct mixing method, and the results showed the incorporation of $\mathrm{B}$ in CFRC was beneficial for the improving of crystallinity and oxidation stability. Saidaminova et al prepared a $\mathrm{H}_{3} \mathrm{BO}_{3}$ modified $\mathrm{EG}$ through electrochemical oxidation of graphite- $\mathrm{H}_{2} \mathrm{SO}_{-}-\mathrm{H}_{3} \mathrm{BO}$ system, ${ }^{29}$ and the results showed that the modified EG possessed higher thermal stability by $200{ }^{\circ} \mathrm{C}$ than the referenced EG. And then, the oxidized graphite was synthesized with chemical oxidation method in the graphite- $\mathrm{H}_{2} \mathrm{SO}_{4}-\mathrm{H}_{3} \mathrm{BO}_{3}-\mathrm{K}_{2} \mathrm{Cr}_{2} \mathrm{O}_{7}$ system, ${ }^{30}$ and the modification raised the oxidation onset temperature by $200-300^{\circ} \mathrm{C}$. In fact, $\mathrm{H}_{3} \mathrm{BO}_{3}$ is not only an oxidation inhibitor, but also a well-known halogen-free, non-toxic and smoke suppressing FR. $\mathrm{H}_{3} \mathrm{BO}_{3}$ can absorb heat and dehydrate at lower temperature due to its lower melting point. It acts in both the condensed phase and gas phase through an endothermic reaction. The released water vapour can reduce concentration of combustible gas, and furthermore, the residual boric oxide can form a glassy coating on polymer surface, limiting the transfer of heat and mass, as well as oxygen diffusion, and then retarding further combustion. Thereby, $\mathrm{H}_{3} \mathrm{BO}_{3}$ is a kind of FR with good flame retardancy, and it can be solely added or used together with others to get better efficiency. ${ }^{31-34}$

To get a kind of EG with low the sulfur content, well dilatability and flame retardancy, this research is to prepare $\mathrm{H}_{3} \mathrm{BO}_{3}$ modified $\mathrm{EG}$ (written as $\mathrm{EG}_{\mathrm{B}}$ ) through flake graphite intercalation reaction with $\mathrm{H}_{2} \mathrm{SO}_{4}$ as main intercalator and $\mathrm{H}_{3} \mathrm{BO}_{3}$ as assistant intercalator simultaneously. The preparation method was founded and energy dispersive spectroscopy (EDS) was used to confirm the change of sulfur relative content. Scanning electron microscope, X-ray diffraction spectroscopy (XRD) and Fourier transform infrared spectroscopy (FTIR) were employed to characterize the structure and main functional group. Meanwhile, with linear low density polyethylene (LLDPE) as flame retarded matrix, the flame retardancy of $\mathrm{EG}_{\mathrm{B}}$, referenced $\mathrm{EG}$ (intercalated with only $\mathrm{H}_{2} \mathrm{SO}_{4}$ ), $\mathrm{H}_{3} \mathrm{BO}_{3}$ and $\mathrm{EG} / \mathrm{H}_{3} \mathrm{BO}_{3}$ (a mechanical mixture) were all tested. Furthermore, to improve the LOI value, vertical combustion UL-94 level 
and suppress the existed "popcorn effect" simultaneously, APP was added together in view of the reported synergistic effect between the two retardants. ${ }^{35,36}$ LOI and UL-94 rating tests, thermal gravimetric and differential thermal gravimetric (TG/DTG) analyses were performed to investigate the flame retarded performance and the thermal stability. Electron microscope was applied to observe the residual char morphology.

\section{EXPERIMENTAL}

Raw Materials and Sample Preparation: Natural flake graphite (average particle size of $0.30 \mathrm{~mm}$, carbon content of $92 \%$ ) was provided by Action Carbon CO. LTD, Baoding, China. LLDPE (7042, $0.918 \mathrm{~g} \mathrm{~cm}^{-3}$, melt index 2.0 $\mathrm{g} \mathrm{min}^{-1}$ ) was purchased from Tianjin, China. APP (II, $\mathrm{n}>1000$ ) was purchased from Sichuan, China. $\mathrm{H}_{3} \mathrm{BO}_{3}$ and $\mathrm{H}_{2} \mathrm{SO}_{4}(98 \%)$ were all analytical reagents and used as received.

Preparation of $E_{B}$ and the referenced EG: Firstly, the reactants were weighed according to a definite mass ratio of graphite $\mathrm{C}: \mathrm{H}_{2} \mathrm{SO}_{4}(98 \%): \mathrm{KMnO}_{4}: \mathrm{H}_{3} \mathrm{BO}_{3}$, and $\mathrm{H}_{2} \mathrm{SO}_{4}$ was diluted to a demanded $\mathrm{wt} \%$ with deionized water before reaction. Then, the quantified reactants were mixed in the order of diluted $\mathrm{H}_{2} \mathrm{SO}_{4}, \mathrm{H}_{3} \mathrm{BO}_{3}, \mathrm{C}$ and $\mathrm{KMnO}_{4}$ in a $250 \mathrm{~mL}$ beaker and stirred at a controlled temperature using a water bath. When the reaction finished, the solid phase was washed with deionized water and dipped in water for $2.0 \mathrm{~h}$ until $\mathrm{pH}$ value of the waste water reached to 6.0-7.0, then filtrated and dried at $50-60{ }^{\circ} \mathrm{C}$ for $5.0 \mathrm{~h}$. The influence of various factors on dilatability of the $\mathrm{EG}_{\mathrm{B}}$ were optimized through single-factor tests including the dosages of $\mathrm{H}_{2} \mathrm{SO}_{4}$ ( $98 \mathrm{wt} \%$ ), $\mathrm{KMnO}_{4}, \mathrm{H}_{3} \mathrm{BO}_{3}$ and $\mathrm{H}_{2} \mathrm{SO}_{4}$ concentration, reaction temperature and time. Feasible conditions of $\mathrm{EG}_{\mathrm{B}}$ preparation were finally identified as: mass ratio of $\mathrm{C}: \mathrm{KMnO}_{2}: \mathrm{H}_{2} \mathrm{SO}_{4}(98 \%): \mathrm{H}_{3} \mathrm{BO}_{3}$ was $1.0: 0.4: 5.0: 0.6$, the concentrated $\mathrm{H}_{2} \mathrm{SO}_{4}$ was diluted to $78 \mathrm{wt} \%$ before reaction; intercalation reaction was totally maintained for 40 min at $40{ }^{\circ} \mathrm{C}$. Initiation expansion temperature (detected with DHG-9075A oven, temperature precision $\pm 0.1^{\circ} \mathrm{C}$, Shanghai, China) $)^{37}$ and the maximum EV (detected with SX3-4-13 Muffle furnace, temperature precision $\pm 0.1-0.4 \%{ }^{\circ} \mathrm{C}$, Tientsin, China) of the prepared $\mathrm{EG}_{\mathrm{B}}$ are $141{ }^{\circ} \mathrm{C}$ and $570 \mathrm{~mL}$ $\mathrm{g}^{-1}$, respectively.

Compared with $\mathrm{EG}_{\mathrm{B}}$, the referenced $\mathrm{EG}$ with only $\mathrm{H}_{2} \mathrm{SO}_{4}$ as intercalator was prepared at the mass ratio $\mathrm{C}: \mathrm{KMnO}_{4}: \mathrm{H}_{2} \mathrm{SO}_{4}(98 \%)$ of 1.0:0.4:5.0 under the same condition mentioned in the preparation of $\mathrm{EG}_{\mathrm{p}}$. Its initial expansion temperature and $\mathrm{EV}$ were detected as $150{ }^{\circ} \mathrm{C}$ and $500 \mathrm{~mL} \mathrm{~g}^{-1}$, respectively.

It's obvious that the addition of $\mathrm{H}_{3} \mathrm{BO}_{3}$ has significant influence on dilatability, reflected by the increase of $\mathrm{EV}$ and adjustment of initial expansion temperature. It is known that $\mathrm{H}_{3} \mathrm{BO}_{3}$ easily dehydrate even at lower temperature; as a result, water vapor would be produced, which is in favor of the increase of EV. At the same time, the intercalated $\mathrm{H}_{2} \mathrm{SO}_{4}$ reacts with graphite causing release of $\mathrm{CO}_{2}, \mathrm{H}_{2} \mathrm{O}$ and $\mathrm{SO}_{2},{ }^{7-9}$ which leads to the expansion of GICs and the formation of the "worm like" expanded graphite particles. ${ }^{10}$ The $\mathrm{EG}_{\mathrm{B}}$ should show better flame retardancy than EG for its good dilatability.

Measurements and characterization: $\mathrm{EDS}$ of $\mathrm{Ca}, \mathrm{Mn}, \mathrm{S}, \mathrm{Si}$ in $\mathrm{EG}_{\mathrm{B}}$ and referenced $\mathrm{EG}$ was detected with KYKY2800B scanning electron microscope (China) under an accelerating voltage of $20 \mathrm{kV}$. The detector resolution and the element detection range were $132 \mathrm{eV}$ and from $\mathrm{Na}$ to $\mathrm{U}$, respectively. Prior to observation, the surfaces were coated with a conductive material.

The FTIR spectra of the prepared $\mathrm{EG}_{\mathrm{B}}$ and $\mathrm{EG}$ were recorded between 4000-400 $\mathrm{cm}^{-1}$ using a FTIR spectrometer (FTS-40, America Biorad ) with a resolution of $2 \mathrm{~cm}^{-1}$.

XRD pattern was obtained with an Y2000 X-ray diffractometer (Dandong, China), under the operation condition of $40 \mathrm{kV}, 30 \mathrm{~mA}$, employing Ni-filtered $\mathrm{Cu} \mathrm{K}$ radiation with $2 \theta$ ranging from $10^{\circ}$ to $70^{\circ}$.

FRs were added into melting LLDPE ( processing temperature was not less than $120^{\circ} \mathrm{C}$ ) in Muller (Jiangsu, China), the mixtures were pressed at $140^{\circ} \mathrm{C}$ and $10 \mathrm{MPa}$, and then chopped into slivers with size of $120.0 \times 6.0 \times 3.0 \mathrm{~mm}^{3}$ and $127.0 \times 13.0 \times 3.0 \mathrm{~mm}^{3}$, respectively.

LOI test was used to evaluate the combustion property of the flame retarded LLDPE composites with a size of $120.0 \times 6.0 \times 3.0 \mathrm{~mm}^{3}$, and it was detected using a JF-3 LOI instrument (Chengde, China) according to Standard of GB/T2406-1993. At the same time, vertical burning tests were performed using a HC-3 vertical burning instrument (Tientsin, China) on sheets of size $127.0 \times 13.0 \times 3.0 \mathrm{~mm}^{3}$ according to the standard UL 94-1996.

In thermal analysis of TG/DTG (STA 449C, Germany), about $10.0 \mathrm{mg}$ sample, laid in porcelain crucible, was detected under $\mathrm{N}$ atmosphere with a flux of $25 \mathrm{~mL} \mathrm{~min}-1$ and heated from about $35^{\circ} \mathrm{C}$ to $800^{\circ} \mathrm{C}$ at a heating rate of $10{ }^{\circ} \mathrm{C} \mathrm{min}^{-1}$. A TM3000 Electron microscope (Japan) was used to observe the surface and section morphology of specimens.

\section{RESULTS AND DISCUSSION}

EDS analysis of material and GICs: EDS results listed in Table 1 present the main surface elements except carbon, oxygen and boron (the element detection range of the used detector is from $\mathrm{Na}$ to $\mathrm{U}$ ) and their relative percentage composition in natural graphite, $\mathrm{EG}_{\mathrm{B}}$ and referenced $\mathrm{EG}$, respectively. As can be seen, except $\mathrm{C}$ element, the natural graphite still consists of $\mathrm{S}, \mathrm{Mn}, \mathrm{Si}$ and $\mathrm{Ca}$. In the referenced $\mathrm{EG}$, the $\mathrm{S}$ content is relative higher, which reveals the intercalation of $\mathrm{H}_{2} \mathrm{SO}_{4} / \mathrm{HSO}_{4} \cdot{ }^{-10}$ Although the $\mathrm{S}$ content in $\mathrm{EG}_{\mathrm{B}}$ is still higher than that of natural graphite, it's lower than that of $\mathrm{EG}$, which dues to the assistant intercalation of $\mathrm{H}_{3} \mathrm{BO}_{3}$. Therefore, $\mathrm{EG}_{\mathrm{B}}$ will release less $\mathrm{SO}_{2}$ gas than the referenced EG.

Table 1 Surface composition of natural graphite, $\mathrm{EG}$ and $\mathrm{EG}_{\mathrm{B}}$ determined by EDS a

\begin{tabular}{|c|c|c|c|}
\hline \multirow{2}{*}{$\begin{array}{c}\text { Element relative } \\
\mathrm{wt} \%\end{array}$} & \multicolumn{3}{|c|}{ Specimens } \\
\cline { 2 - 4 } & Natural graphite & $\mathrm{EG}_{\mathrm{B}}$ & $\begin{array}{c}\text { Referenced } \\
\mathrm{EG}\end{array}$ \\
\hline $\mathrm{Si}$ & 2.56 & 5.3 & 3.8 \\
\hline $\mathrm{S}$ & 65.2 & 75.2 & 83.6 \\
\hline $\mathrm{Ca}$ & 6.98 & 7.4 & 2.8 \\
\hline $\mathrm{Mn}$ & 20.9 & 12.1 & 9.8 \\
\hline Total & 95.6 & 100.0 & 100.0 \\
\hline
\end{tabular}

${ }^{a}$ The detector resolution and the element detection range were $132 \mathrm{eV}$ and from $\mathrm{Na}$ to $\mathrm{U}$, respectively.

FTIR analysis of material and GICs: Figure 1 shows FTIR spectra of the prepared $\mathrm{EG}_{\mathrm{B}}$ and referenced EG. As can be seen from the results, two samples both show the characteristic stretching vibrations absorption peaks of $-\mathrm{OH}\left(3430-3420 \mathrm{~cm}^{-1}\right)$, caused by intercalation of $\mathrm{H}_{2} \mathrm{SO}_{4} / \mathrm{HSO}_{4}^{-}$or $\mathrm{H}_{3} \mathrm{BO}_{3}$. At the same time, the peaks at about $1620 \mathrm{~cm}^{-1}$ are the specific absorption peaks of $\mathrm{C}=\mathrm{C}$ stretching vibration, originating from graphite conjugated structure. The strong stretching vibration absorption peak of $\mathrm{S}=\mathrm{O}$ is observed in $\mathrm{EG}(1118$ $\mathrm{cm}^{-1}$ ), but there are strong superimposed peaks at $1463 \mathrm{~cm}^{-1}$ and $1190 \mathrm{~cm}^{-1}$ in the FTIR of $\mathrm{EG}_{\mathrm{B}}$, it is because the absorption peaks of $\mathrm{S}=\mathrm{O}$ and $\mathrm{B}=\mathrm{O}$ are both appear in the range of $1500-1100 \mathrm{~cm}^{-1}$ as reported. ${ }^{38}$ Furthermore, the peaks in the range of $800-600 \mathrm{~cm}^{-1}$ in the $\mathrm{EG}_{\mathrm{B}}$ belong to B-O specific absorption. ${ }^{39}$ The results indicate the intercalation of intercalators.

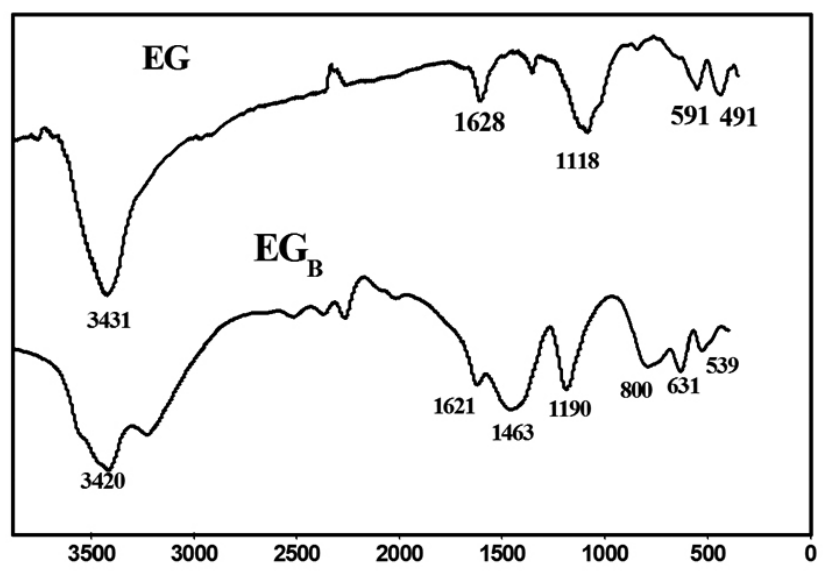

Figure 1 FTIR analysis of the referenced $\mathrm{EG}$ and $\mathrm{EG}_{\mathrm{B}}$

Morphology property of natural graphite and $E G_{p}$ : Figure 2 presents electron microscope photographs of natural graphite and $\mathrm{EG}_{\mathrm{B}}$. As shown in Figure 2 (a) the cross-section of natural graphite (amplified by a factor of 20000), layer structures of natural graphite are compact, and the layers distance is very small and regular. However, the cross-section of $\mathrm{EG}_{\mathrm{B}}$ (shown in Figure 2 (b), amplified by a factor of 1000) shows that layers distance has been enlarged, and the boundary layers are loose and damaged. It can be inferred that the intercation forces between the $\mathrm{EG}_{\mathrm{B}}$ layers are weaken due to the oxidation of $\mathrm{KMnO}_{4}$ and intercalation of $\mathrm{H}_{2} \mathrm{SO}_{4}$ and $\mathrm{H}_{3} \mathrm{BO}_{3}$. 


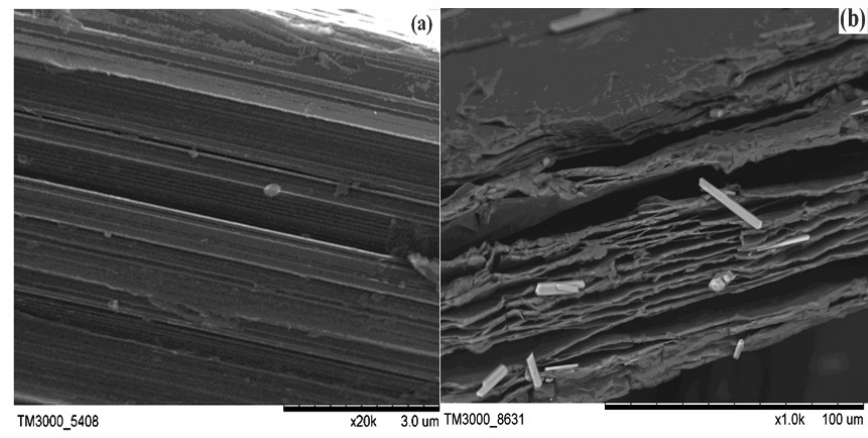

Figure 2 Morphology property of natural graphite (a) and $\mathrm{EG}_{\mathrm{B}}$ (b)

XRD analysis of the GICs: XRD analysis for natural graphite, $\mathrm{EG}_{\mathrm{B}}$ and the referenced EG were performed. As shown in Figure 3 (a), the two peaks at $26.4^{\circ}$ (corresponding an interplanar crystal spacing of $0.334 \mathrm{~nm}$ ) and $55.5^{\circ}$ (corresponding an interplanar crystal spacing of $0.167 \mathrm{~nm}$ ) are two characteristic peaks of natural graphite. While, XRD patterns in Figure 3 (b) and (c) all show two similar peaks as natural graphite in the range of $25^{\circ}-27^{\circ}$ and $50^{\circ}-60^{\circ}$, which indicates both $\mathrm{EG}$ and $\mathrm{EG}_{\mathrm{B}}$ all keep the same layer structure as natural graphite. But it is worthy to note that the diffraction peaks in the range of $25^{\circ}-27^{\circ}$ transfer to smaller angle of $26.3^{\circ}$ and $26.2^{\circ}$, respectively. At the same time, each corresponds to a big interplanar crystal spacing of 0.338 $\mathrm{nm}$ for $\mathrm{EG}$ and $0.339 \mathrm{~nm}$ for $\mathrm{EG}_{\mathrm{B}}$. This can be explained that natural graphite is oxidized by $\mathrm{KMnO}_{4}$ and then exhibited positive charge. Then gap between graphite layers is extended due to the repulsion, and intercalating reaction can proceed between graphite and intercalator. The positive charge of the oxidized graphite network is balanced by negatively charged acid anions and also includes acid molecules. ${ }^{36,40,41}$ Results confirm that intercalators have been inserted into graphite layers.

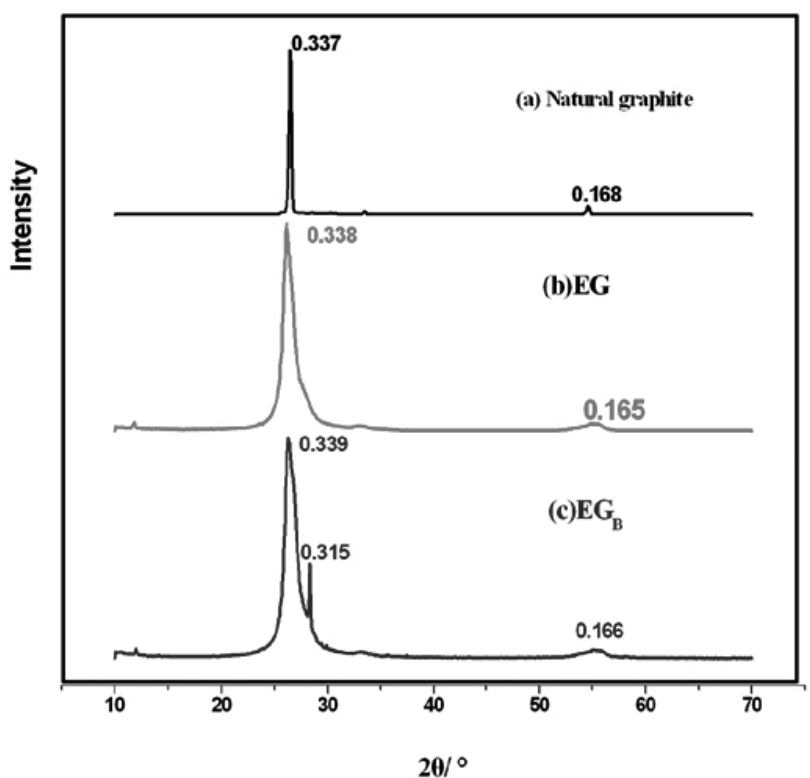

Figure 3 XRD analysis of natural graphite (a), EG (b) and $\mathrm{EG}_{\mathrm{B}}(\mathrm{c})$

Flame Retardancy of composites: The processing temperature of LLDPE is normally lower than $120{ }^{\circ} \mathrm{C}$, so the prepared GICs can be used as FRs. The flame retarded LLDPE specimens were prepared following the above mentioned method, weight percentage between FRs and polymer was listed in Table 2. LOI detection and vertical combustion tests were carried out to evaluate flame retardancy and observe ignition, expansion-extinguishing process, melt-dripping phenomenon. The results were also listed in Table 2.
Table 2 Specimen components and their combustion properties ${ }^{b}$

\begin{tabular}{|c|c|c|c|c|}
\hline \multirow{2}{*}{ Specimens } & \multicolumn{2}{|c|}{ LOI \% } & \multirow{2}{*}{$\begin{array}{c}\text { UL-94 } \\
\text { Level }\end{array}$} & \multirow{2}{*}{$\begin{array}{c}\text { Melt } \\
\text { Dripping }\end{array}$} \\
\hline & LOI $_{\text {exp }}$ & $\mathrm{LOI}_{\text {cal }}$ & & \\
\hline 100 LLDPE & 17.6 & & - & Yes \\
\hline 70LLDPE/30EG & 25.1 & & $\mathrm{~V}-1$ & No \\
\hline 70LLDPE/30EG & 30.2 & 23.8 & $\mathrm{~V}-0$ & No \\
\hline $70 \mathrm{LLDPE} / 30 \mathrm{H}_{3} \mathrm{BO}_{3}$ & 19.2 & & - & Yes \\
\hline $70 \mathrm{LLDPE} / 18 \mathrm{EG} / 12 \mathrm{H}_{3} \mathrm{BO}_{3}$ & 26.5 & 23.8 & $\mathrm{~V}-1$ & No \\
\hline 70LLDPE/30APP & 20.0 & & - & Yes \\
\hline 70LLDPE/20EG $/ 10 \mathrm{APP}$ & 33.0 & 26.8 & $\mathrm{~V}-0$ & No \\
\hline 70LLDPE/15EG $/ 15 \mathrm{APP}$ & 32.4 & 25.1 & $\mathrm{~V}-0$ & No \\
\hline 70LLDPE/10EG $\mathrm{EG}_{\mathrm{B}} / 20 \mathrm{APP}$ & 32.0 & 23.4 & $\mathrm{~V}-0$ & No \\
\hline
\end{tabular}

${ }^{b}$ Component contents are expressed as wt $\%$. 70LLDPE/18EG/12 $\mathrm{H}_{3} \mathrm{BO}_{3}$ specimen is prepared by mechanical mixing of LLDPE (70 wt \%) with the referenced EG $(18 \mathrm{wt} \%)$ and $\mathrm{H}_{3} \mathrm{BO}_{3}(12 \mathrm{wt} \%)$. Furthermore, the ratio of EG: $\mathrm{H}_{3} \mathrm{BO}_{3}$ (18:12) was calculated according to the ratio of $\mathrm{C}: \mathrm{H}_{3} \mathrm{BO}$ (determinate to be 1:0.6) in $\mathrm{EG}_{\mathrm{B}}$ preparation (herein, it was supposed that all $\mathrm{H}_{3} \mathrm{BO}_{3}$ were inserted in the intercalation reaction).

As shown in Table 2, LOI of pure LLDPE is only $17.6 \%$, and the combustion accompanies with serious molten drop at the same time (as shown in Figure 4 (a)). LOI values of flame retarded LLDPE composites are all higher than that of pure matrix. Addition of $30 \mathrm{wt} \%$ referenced EG improves the LOI of 70LLDPE/30EG composite to $25.1 \%$, and the UL-94 level reaches V-1. Noticeably, the addition of the same amount of the prepared $\mathrm{EG}_{\mathrm{B}}$ improves LOI value and UL-94 level of $70 \mathrm{LLDPE} / 30 \mathrm{EG}_{\mathrm{B}}$ to $30.2 \%$ and $\mathrm{V}-0$ respectively. These results indicate the assistant intercalation of $\mathrm{H}_{3} \mathrm{BO}$ obviously improves flame retardancy for LLDPE. This is because the intercalated $\mathrm{H}_{3} \mathrm{BO}_{3}$ can not only play an retardant role, but also its thermo-decomposition residues $\mathrm{B}_{2} \mathrm{O}_{3}$ can also increase the cohesiveness and density of the protective intumescent carbonaceous char generating from EG expansion, ${ }^{22-44}$ which is helpful to improving its shielding, adiabaticity and protecting the polymeric matrix from degrading into gases. While, the addition of $\mathrm{EG}_{\mathrm{B}}$ or $\mathrm{EG}$ can all reduce the dripping phenomena and raise the fire safety property, which is attributed to the protective intumescent carbonaceous char (as shown in Figure 4 (b) and (c)) formed on polymer surface by $\mathrm{EG}_{\mathrm{B}}$ or $\mathrm{EG}$ expansion. It can be seen that the mechanical mixture of $\mathrm{H}_{3} \mathrm{BO}_{3}$ with LLDPE make 70LLDPE/30 $\mathrm{H}_{3} \mathrm{BO}_{3}$ show a weaker flame retardancy than the referenced EG, but its combination with EG presents an improved anti-flame efficiency, indicating a higher LOI value of $26.5 \%$ than the theoretic calculated LOI value of $23.8 \%$. Remarkably, the chemical intercalated $\mathrm{H}_{3} \mathrm{BO}_{3}$ in $\mathrm{EG}_{\mathrm{B}}$ is more effectual than the simple mechanical mix. The most probable reasons should be that the mixing uniformity of $\mathrm{H}_{3} \mathrm{BO}_{3}$ with graphite is higher in $\mathrm{EG}_{\mathrm{B}}$ than the mechanical mix of EG with $\mathrm{H}_{3} \mathrm{BO}_{3} \cdot 29,30$

At the same time, the anti-flame efficiency of APP for LLDPE and its synergetic efficiency with $\mathrm{EG}_{\mathrm{B}}$ were investigated. When it is solely added at $30 \mathrm{wt} \%$, LOI of the 70LLDPE/30APP specimen is only improved to $20.0 \%$, and the melt-dripping and ignition still can not be avoided. While, addition of $\mathrm{EG}_{\mathrm{B}}$ and APP at different $\mathrm{wt} \%$ to LLDPE show that the combination can not only increase LOI value, but also all improve the UL-94 level to V-0 simultaneously. Meanwhile, LOI values were all obviously higher than the calculated $\mathrm{LOI}_{\mathrm{cal}}$ according to the single $\mathrm{EG}_{\mathrm{B}} \mathrm{wt} \%$, APP $\mathrm{wt} \%$ and their LOI values. Therefore, it may be inferred that there is synergistic efficiency between the two FRs. Meanwhile, the $\mathrm{APP} / \mathrm{EG}_{\mathrm{B}}$ ratio has an important influence on flame retardancy, and the tested optimum component is 10:20 as shown in 70LLDPE/10APP/20EG $\mathrm{E}_{\mathrm{B}}$ specimen, the LOI and UL-94 level are $33.0 \%$ and $\mathrm{V}-0$ respectively. 

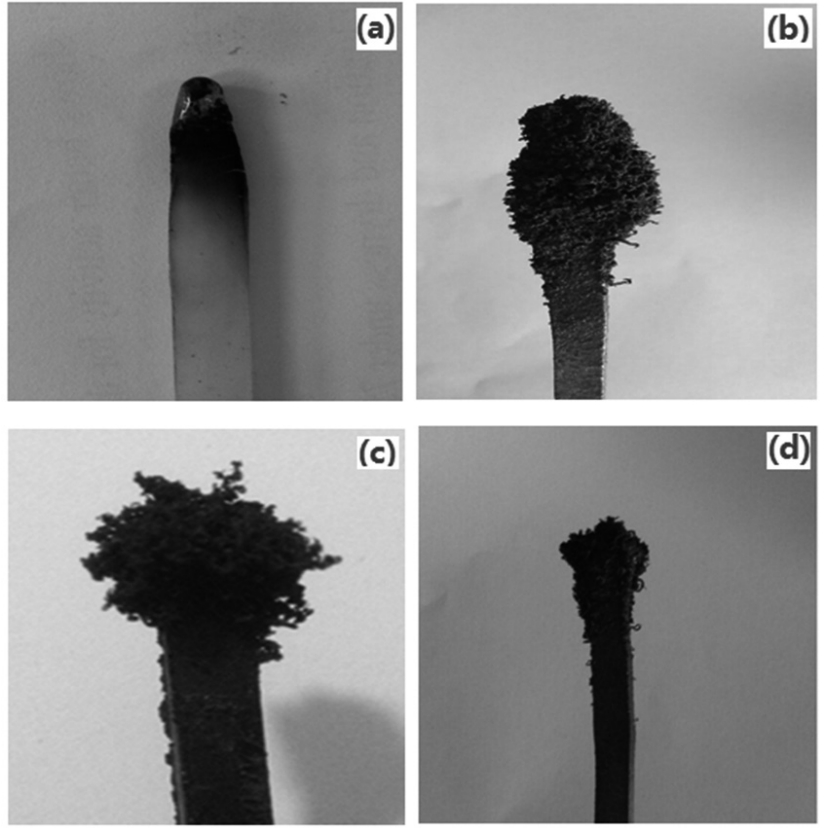

Figure 4 The combustion behavior of LLDPE specimens in vertical burning tests LLDPE (a); 70LLDPE/30EG $\mathrm{B}_{\mathrm{B}}$ (b); 70LLDPE/30EG (c); 70LLDPE/20EG/10APP (d)

Morphology of the combustion residue: In the burn process, the formation of effective protective char can improve flame retardancy. Therefore, residue morphology of the flame retarded LLDPE after their LOI tests were examined by electron microscope. Figure 5 (a) shows the incision section of $70 \mathrm{LLDPE} / 30 \mathrm{EG}_{\mathrm{B}}$ composite after combustion, a regular "open-cellular" structure on the surface is observed due to the expansion of $\mathrm{EG}_{\mathrm{B}}$ (showing the "popcorn effect"), originating from blowing gases in redox reaction between residual $\mathrm{H}_{2} \mathrm{SO}_{4}$ and the graphite. Finally, discontinuity and low mechanical strength of the residue cause the 70LLDPE/30EG $\mathrm{EG}_{\mathrm{B}}$ system easily break and a decrease of shielding function for heat and mass transfer (the tensile strength of 70LLDPE/30EG is detected as $6.8 \mathrm{MPa}$ ). The residue incision section of $70 \mathrm{LLDPE} / 10 \mathrm{APP} / 20 \mathrm{EG}_{\mathrm{B}}$ shown in Figure 5 (b) is relatively continuous and compact due to the conglutination of APP decomposition products (the tensile strength of $70 \mathrm{LLDPE} / 10 \mathrm{APP} / 20 \mathrm{EG}_{\mathrm{B}}$ is detected as $\left.7.3 \mathrm{MPa}\right) ;{ }^{17}$ this structure inhibits the "popcorn effect" and provides a shield that insulates the substrate from radiant heat, and avoids the direct contact between substrate and flame. It is the continuous and compact residual that makes $70 \mathrm{LLDPE} / 10 \mathrm{APP} / 20 \mathrm{EG}_{\mathrm{B}}$ composite hold higher LOI value and thermal stability than $70 \mathrm{LLDPE} 30 \mathrm{EG}_{\mathrm{B}}$ composite.

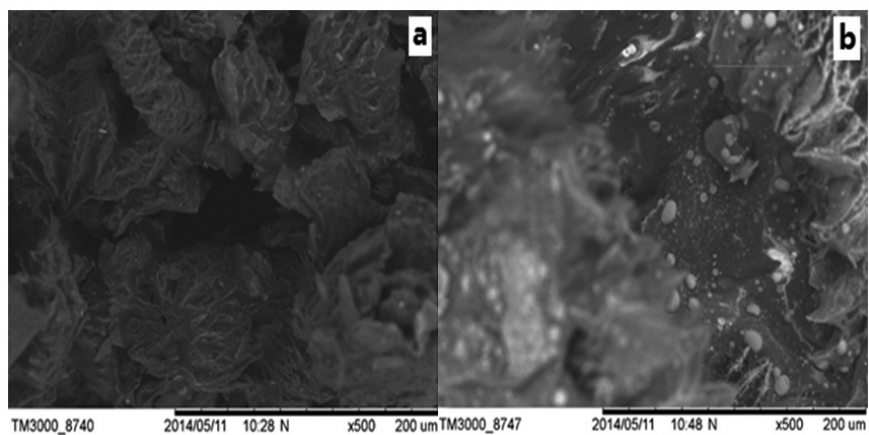

Figure 5 Electron microscopy morphology of $70 \mathrm{LLDPE} / 30 \mathrm{EG}_{\mathrm{B}}$ (a) and $70 \mathrm{LLDPE} / 10 \mathrm{APP} / 20 \mathrm{EG}_{\mathrm{B}}$ (b) after LOI tests.

Thermal stabilities-TG/DTG analysis: Thermal stability of flame retarded LLDPE is related to the addition of FRs. TG/DTG under $\mathrm{N}_{2}$ atmosphere was used to evaluate the thermal degradation properties of the referenced EG, $\mathrm{EG}_{\mathrm{B}}, 70 \mathrm{LLDPE} / 30 \mathrm{EG}, 70 \mathrm{LLDPE} / 30 \mathrm{EG}_{\mathrm{B}}$ and $70 \mathrm{LLDPE} / 10 \mathrm{APP} / 20 \mathrm{EG}_{\mathrm{B}}$, and the results were shown in Figure 6 and Table 3.
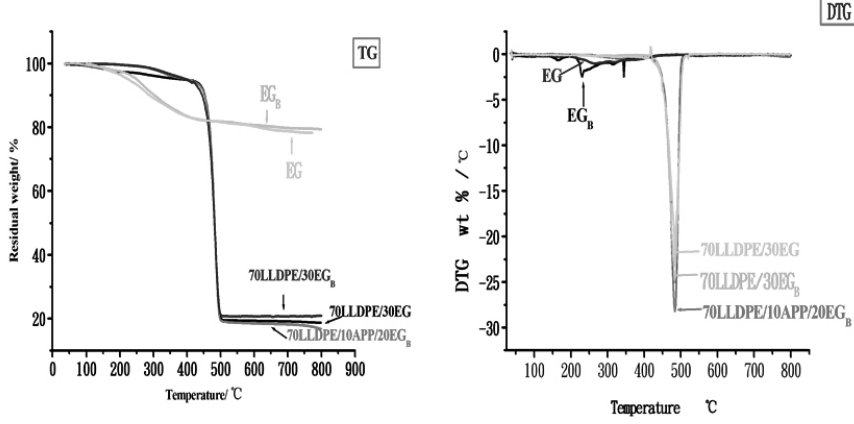

Figure 6 TG and DTG analysis of samples

Table 3 Thermoanalysis data of specimens in $\mathrm{N}_{2}$ atmosphere ${ }^{\mathrm{c}}$

\begin{tabular}{|c|c|c|c|c|}
\hline \multirow{2}{*}{ Specimens } & $\mathrm{T}_{5 \%}$ & $\mathrm{~T}_{\max }$ & $\mathrm{R}_{\max }$ & $\begin{array}{c}\text { Residue } \\
\left(800{ }^{\circ} \mathrm{C}\right)\end{array}$ \\
\cline { 2 - 5 } & $/{ }^{\circ} \mathrm{C}$ & $/{ }^{\circ} \mathrm{C}$ & $/\left(\% \mathrm{~min}^{-1}\right)$ & $/ \%$ \\
\hline $\mathrm{EG}$ & 248 & 267 & -1.03 & 78.2 \\
\hline $\mathrm{EG}_{\mathrm{B}}$ & 223 & 231 & -2.45 & 79.4 \\
\hline $70 \mathrm{LLDPE} / 30 \mathrm{EG}$ & 396 & 485 & -23.2 & 18.7 \\
\hline 70LLDPE/30EG & 384 & 483 & -25.0 & 20.9 \\
\hline 70LLDPE/10APP/20EG & 396 & 484 & -28.2 & 16.8 \\
\hline
\end{tabular}

${ }^{\mathrm{c}} \mathrm{T}_{5}$ : the temperature at which $5 \%$ weight loss occurring, ${ }^{\circ} \mathrm{C}$.

$\mathrm{T}_{\max }$ : the temperature corresponding to the maximum decomposition rate, ${ }^{\circ} \mathrm{C}$

$\mathrm{R}_{\max }:$ the maximum decomposition rate, $\% \mathrm{~min}^{-1}$.

Compared with the flame retarded LLDPE composites, mass loss of the referenced $\mathrm{EG}$ and $\mathrm{EG}_{\mathrm{B}}$ is more moderate. For $\mathrm{EG}$, the weight lose mainly occurs among $250-450{ }^{\circ} \mathrm{C}$ with a peak of $267^{\circ} \mathrm{C}$ and the maximum decomposition rate $\left(\mathrm{R}_{\max }\right)$ of $-1.03 \% \mathrm{~min}^{-1}$ as shown in Table 3 , wherein $\mathrm{CO}_{2}, \mathrm{H}_{2} \mathrm{O}$ and $\mathrm{SO}_{2}$ gas released during redox reaction between graphite and the intercalated $\mathrm{H}_{2} \mathrm{SO}_{4} /$ $\mathrm{HSO}_{4},{ }^{16}$ and leads to the generation of "worm like" expanded graphite. As for $\mathrm{EG}_{\mathrm{B}}$, besides redox reaction between graphite and $\mathrm{H}_{2} \mathrm{SO}_{4}$, dehydration of the intercalated $\mathrm{H}_{3} \mathrm{BO}_{3}$ in or between molecules and its fusion occurs in the range of $100-300{ }^{\circ} \mathrm{C}$, which leads to a lower $\mathrm{T}_{5}$ (temperature at which $5 \%$ weight loss occurring), $\mathrm{T}_{\max }$ (temperature corresponding to the maximum decomposition rate) and higher $\mathrm{R}_{\text {mo }}$ of $-2.45 \% \mathrm{~min}^{-1}$. Then the produced glassy $\mathrm{B}_{2} \mathrm{O}_{3}$ coating act as filler and binder for the swollen expanded graphite and then form more compacter carbonaceous char layer as shown in Figure 4 (b). As a result, $E_{B}$ keeps a higher residual char yield of $79.4 \%$ at $800{ }^{\circ} \mathrm{C}$ than the referenced $\mathrm{EG}$ of $78.2 \%$, which confirms its higher thermal stability and leads to a relative remarkable flame retardancy indicated by LOI value. ${ }^{14,36}$

For those flame retarded LLDPE composites with a FR dose of $30 \mathrm{wt} \%$ all show the same weight loss tendency, but they hold different $\mathrm{T}_{5}, \mathrm{~T}$ and $\mathrm{R}_{\text {. The }}$ 70LLDPE/30EG $\mathrm{E}_{\mathrm{B}}$ composite shows a lower thermal stability than $70 \mathrm{LLDPE} / 30 \mathrm{EG}$ composite when the temperature is lower than $490^{\circ} \mathrm{C}$, which is indicated by its lower decomposition temperature corresponding to $\mathrm{T}_{5}$ and $\mathrm{T}_{\max }$ and higher $\mathrm{R}_{\max }$ of $-25.0 \% \mathrm{~min}^{-1}$ as shown in Table 3 . The results are caused by the additional decomposition function of the intercalated $\mathrm{H}_{3} \mathrm{BO}_{3}$ as mentioned in the TG of $\mathrm{EG}_{\mathrm{B}}$. But once the expansion of $\mathrm{EG}_{\mathrm{B}}$, fusion and dehydration of $\mathrm{H}_{3} \mathrm{BO}$ finished, the matrix will covered with more residual than 70LLDPE/30EG, which can be indicated by their final residual yield. As for the 70LLDPE/10APP/20EG $\mathrm{E}_{\mathrm{B}}$ composite, it show a higher $\mathrm{R}$ of $-28.2 \% \mathrm{~min}^{-1}$ than the single $\mathrm{EG}$ or $\mathrm{EG}_{\mathrm{B}}$ retarded LLDPE. The results are caused by the additional decomposition function of the added APP. As for the residual weight, although $70 \mathrm{EVA} / 10 \mathrm{APP} / 20 \mathrm{EG}_{\mathrm{B}}$ system holds a lower residual carbon (caused by the reduced carbon resource) than $70 \mathrm{LLDPE} / 30 \mathrm{EG}_{\mathrm{B}}$ system, it presents a higher flame retardancy indicated by LOI. The reason is that with the help of the conglutination of APP decomposing products, the swollen expanded graphite can form a compacter carbonaceous char layer. As for the EG/APP system, the carbonaceous char compaction plays a more important role in improving thermal stability and flame retardancy than the residual carbon weight. ${ }^{45}$ 
Possible Mechanism of flame retardance: According to the LOI and UL94 tests results, it can be indicated that the flame retardancy of LLDPE can be greatly improved by $\mathrm{EG}_{\mathrm{B}}$ especially the combination of $\mathrm{EG}_{\mathrm{B}}$ with $\mathrm{APP}$, which shows a typical synergetic flame retardancy behavior. Through the analysis of TG/DTG and the residual morphology, the synergistic mechanism was proposed for this system. In the gas phase, the non-flammable gases, such as $\mathrm{CO}_{2}, \mathrm{SO}_{2}, \mathrm{NH}_{3}, \mathrm{~N}_{2}$ and $\mathrm{H}_{2} \mathrm{O}$, released through decomposition or dehydration of $\mathrm{EG}_{\mathrm{B}}, \mathrm{H}_{3} \mathrm{BO}_{3}$ and $\mathrm{APP}$, which can dilute the combustible gases. In the condensed phase, $\mathrm{EG}_{\mathrm{B}}$ and its intercalated $\mathrm{H}_{3} \mathrm{BO}_{3}$, the additional added APP play important role in combustion. Initially, the "worm like" char is formed through the expansion of $\mathrm{EG}_{\mathrm{B}}$ when the temperature is above $141^{\circ} \mathrm{C}$ (initiation expansion temperature of $\mathrm{EG}_{\mathrm{B}}$ ), but the char is slight [shown as Figure 4 (b)] and can not effectively endure heat flux. Along with the raising of combustion temperature, the further dehydration or fusion of $\mathrm{H}_{3} \mathrm{BO}_{3}$ occur, and lead to the formation of $\mathrm{B}_{2} \mathrm{O}_{3}$ glassy coating, which can increase the cohesiveness and density of the protective intumescent char generating from $\mathrm{EG}_{\mathrm{B}}$ expansion. At the same time, polyphosphoric acid generated from APP increased the melt viscosity, which can strengthen the char barrier for its strong adhesion effect. The char structure of $70 \mathrm{LLDPE} / 10 \mathrm{APP} / 10 \mathrm{EG}_{\mathrm{B}}$ [Figure 4 (d) and Figure $5(\mathrm{~b})$ ] presents a thicker and denser char layer than $70 \mathrm{LLDPE}_{3} 30 \mathrm{EG}_{\mathrm{B}}$ [Figure 5 (a)]. Thus, the transfer of gas and heat is retarded by this insulative layer.

\section{CONCLUSIONS}

$\mathrm{EG}_{\mathrm{B}}$ was successfully prepared with $\mathrm{H}_{2} \mathrm{SO}_{4}$ and $\mathrm{H}_{3} \mathrm{BO}_{3}$ as intercalators with chemical oxidation intercalation method. Compared with the referenced $\mathrm{EG}$, the $\mathrm{EG}_{\mathrm{B}}$ indicated a better dilatability, flame retardancy and environmentfriendly property. EDS, FTIR, SEM and XRD confirmed that the oxidation and intercalation reaction between natural graphite and intercalators could take place. Combustion tests of the flame retarded LLDPE composites showed that $\mathrm{EG}_{\mathrm{B}}$ presented a higher LOI value of $30.2 \%$ than $\mathrm{EG}$ of $25.1 \%$. The combination of $\mathrm{EG}_{\mathrm{B}}$ with APP made the $70 \mathrm{LLDPE} / 10 \mathrm{APP} / 20 \mathrm{EG}_{\mathrm{B}}$ system showed high efficiency; the LOI value and UL-94 level reached $33.0 \%, \mathrm{~V}-0$ respectively. TG/DTG analysis proved $\mathrm{EG}_{\mathrm{B}}$ and $\mathrm{EG}_{\mathrm{B}} / \mathrm{APP}$ could improve LLDPE composites thermal stability at high temperature. Electron microscope photographs indicated that the residual char of sample treated with $\mathrm{EG}_{\mathrm{B}} / \mathrm{APP}$ was more continuous and compact than that of treated with only $\mathrm{EG}_{\mathrm{B}}$. It was concluded that the $\mathrm{EG}_{\mathrm{B}}$ /APP system could improve the char quality which was the key factor in dripping resistance and improving thermal stability of the composites.

\section{ACKNOWLEDGEMENTS}

The authors would like to thank Natural Science Foundation of Hebei Province (CN) (No. B2015201028) and Seedling Project of College of Chemistry and Environmental Science (Hebei University) for financial support.

\section{REFERENCES}

1. J.E. Fischer, T.E. Thompson, Physics Today 31, 36, (2008).

2. G.Q. Liu, M. Yan, New Carbon Mater. 17, 13, (2002).

3. Z.D. Sun, Y.H. Ma, Y. Xu, X.L. Chen, M. Chen, J. Yu, S.C. Hu, Z.B. Zhang, Polym. Eng. Sci. 54, 1162, (2014).

4. C.Q. Wang, F.Y. Ge, J. Sun, Z.S. Cai, Appl. Polym. Sci. 130, 916, (2013).

5. M. Thirumal, D. Khastgir, N.K. Singha, B.S. Manjunath, Y.P. Naik, Appl. Polym. Sci. 110, 2586, (2008).

6. C.F. Kuan, K.C. Tsai, C.H. Chen, H.C. Kuan, T.Y. Liu, C.L. Chiang, Polym. Composite. 33, 872, (2012).

7. H. Shioyama, R. Fujii, Carbon, 25, 771, (1987).

8. H. Ren, Y.F. Kang, Q.J. Jiao, Q.Z. Cui, New Carbon Mater. 21, 315, (2006).

9. M.I. Saidaminov, N.V. Maksimova, P.V. Zatonskih, A.D. Komarov, M.A. Lutfullin, N.E. Sorokina, V.V. Avdeev, Carbon, 59, 337, (2013).

10. S. Duquesne, M.L. Bras, S. Bourbigot, R. Delobel, H. Vezin, G. Camino, B. Eling, C. Lindsay, T. Roels, Fire Mater. 27, 103, (2003).

11. Z.H. Zheng, J.T. Yan, H.M. Sun, Z.Q. Cheng, W.J. Li, H.Y. Wang, X.J. Cui, Polymer Int. 63, 84, (2014).

12. X.L Chen, H. Wu, Z. Luo, B. Yang, S.Y. Guo, J. Yu, Polym. Eng. Sci. 47, 1756, (2007).

13. Z.D. Sun, Y.H. Ma, Y. Xu, X.L. Chen, M. Chen, J. Yu, S.C. Hu, Z.B. Zhang, Polym. Eng. Sci. 54, 1162, (2014).

14. L.L. Ge, H.J. Duan, X.G. Zhang, C. Chen, J.H. Tang, Z.M.J. Li, Appl. Polym. Sci. 126, 1337, (2012).
15. S.G. Hong, S.Y Chang, Fire Mater. 36, 277, (2012).

16. Y.B. Lu, Y.J. Zhang, W.J. Xu, J. Macromol. Sci. 50, 1864, (2011).

17. X.Y. Pang, Y. Tian, M. Q. Weng, Polym. Composite. 36, 1407, (2015).

18. M.K. Song, Master's thesis, Hebei Univ. (2013).

19. S. Duquesne, M.L. Bras, S. Bourbigot, R. Delobel, H. Vezin, G. Camino, B. Eling, C. Lindsay T. Roels, Fire Mater. 27, 103, (2003).

20. L. Chen, Y. Z. Wang, Polym. Adv. Tech. 21, 1, (2010).

21. F.F. Feng, L.J. Qian, Polym. Composite. 35, 301, (2014).

22. Y. Zhang, X.L. Chen, Z.P. Fang, Appl. Polym. Sci. 128, 2424, (2013).

23. H. Seefeldt, U. Braun, M.H. Wagner, Macromol. Chem. Phys. 213, 2370, (2012).

24. L. P. Gao, G.Y. Zheng, Y.H. Zhou, L.H. Hu, G.D. Feng, Y.L. Xie, Ind. Crop. Prod. 50, 638, (2013).

25. L.C. Du, Y.C. Zhang, X.Y Yuan, J.Y. Chen, Polym-Plast Technol. 48, 1002, (2009).

26. D.M. Xu, F. Ding, J. W. Hao, J.X. Du, Chem. J. Chinese Univ. 34, 2674, (2013).

27. O.N. Shornikova, A.V. Dunaev, N.V. Maksimova, V.V. Avdeev, J. Phys. Chem. Solids, 67, 1193, (2006).

28. Y.J. Lee, H.J. Joo, L.R. Radovic, Carbon, 41, 2591, (2003).

29. M.I. Saidaminova, N.V. Maksimovaa, V.V. Avdeeva, J. Mater. Res., 27, $1054,(2012)$

30. M.I. Saidaminov, N.V. Maksimova, N.G. Kuznetsov, N.E. Sorokina, V.V. Avdeev, Inorg. Mater., 48, 258, (2012).

31. T. Hirata, K.E. Werner, J. Appl. Polym. Sci. 33, 1533, (1987).

32. N. Selvakumar, A. Azhagurajan, T.S. Natarajan, M.M.A. Khadir, J. Appl. Polym. Sci. 126, 614, (2012).

33. A.D. Chirico, G. Audisio, F. Provasoli, M. Armanini1, R. Franzese, Makromol. Chem. 74, 343, (1993).

34. S. Ullah, F. Ahmad, P.S.M. Megat Yusoff, J. Appl. Polym. Sci. 128, 2983 , (2013).

35. X.M. Hu, D.M. Wang, J. Appl. Polym. Sci. 129, 238, (2013).

36. D.M. Xu, J.W. Hao, G.S. Liu, S.M. Xie, Acta Polym. Sin. 7, 832, (2013).

37. Z.D. Han, D.W. Zhang, L.M. Dong, X.Y. Zhang, Chinese J. Inorg. Chem. 23, 286, (2007)

38. J. Li, S.P. Xia, S.Y. Gao, Spectrochim. Acta A, 51, 519, (1995).

39. C.F. Zuo, Master thesis, Shanxi Normal University, (2005).

40. L.B. Ebert, Annu. Rev. Mater. Sci. 6, 181, (1976).

41. H. Zabel, S.A. Solin (Eds). Springer Series in Materials Science, 14, 355 , (1990)

42. H. Selig, L.B. Ebert, Adv. Inorg. Chem. Radiochem. 23, 281, (1980).

43. B. Schartel, A. Wei, F. Mohr, M. Kleemeier, A. Hartwig, U. Braun, $J$. Appl. Polym. Sci. 118, 1134, (2010).

44. C.H. Chen, W.H. Yen, H.C. Kuan, C.F. Kuan, C.L. Chiang, Polym. Composite. 31, 18, (2010).

45. H.F. Zhu, Q.L. Zhu, J. Li, K. Tao, L.X. Xue, Q. Yan, Polym. Degrad. Stabil. 96, 183, (2011). 